424

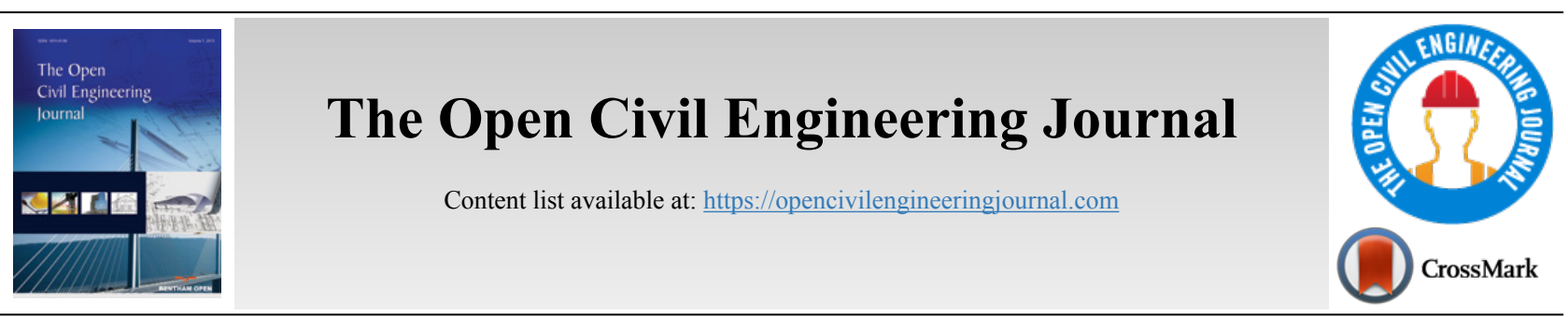

REVIEW ARTICLE

\title{
Guidelines for Geotechnical Finite-Element Modeling
}

\author{
Ahmed Elgamal ${ }^{1, *}$ \\ ${ }^{I}$ Department of Civil Engineering, Mansoura Higher Institute for Engineering and Technology, Mansoura, Egypt
}

\begin{abstract}
:
This paper emphasizes on the required guidelines for establishing a geotechnical finite-element model. The steps that must be taken to construct such a model are explained in a flowchart, and the methodology described therein is illustrated by building a model using commercially available finite-element software. Well-documented experimental test data are used to validate the model results. The effects of the geometry plotting, meshing techniques, and boundary locations are assessed by comparing the model results with the experimental results. To date, various geotechnical constitutive models have been proposed to describe various aspects of actual soil behavior in detail, and the advantages and limitations of five such models are discussed. The model results are subjected to an assessment check. The geotechnical modeler can be decided based on the knowledge base that constitutive models will use as the case.
\end{abstract}

Keywords: Finite element, Model boundaries, Meshing, Constitutive model, Geotechnical engineering, Model results.

\begin{tabular}{l|l|l|l} 
Article History & Received: September 20, 2021 & Revised: November 1,2021 & Accepted: November 8, 2021
\end{tabular}

\section{INTRODUCTION}

In geotechnical engineering, the frequently used term "Finite-Element (FE) modeling" refers to a numerical technique whereby engineering structures and their surrounding soil are discretized into certain numerical elements that obey specific constitutive laws. Because soil behaves in a complicated and nonlinear manner, all methods for modeling it are necessarily numerical [1], and geotechnical engineers tend to use methods based on FE theory. A numerical FE model of a geotechnical problem must simulate the actual field conditions of that problem. The model must capture the complex behavior of the soil to provide accurate deformations, settlement, and straining actions, thereby giving engineers a unique perspective for making evaluations and judgments.

Fig. (1) shows a flowchart that explains the stages of establishing a geotechnical FE model. To explain the modeling stages easily, each stage is illustrated using a selected case study. A study carried out laboratory experiments to provide data to verify associated two-dimensional (2D) and threedimensional (3D) FE models [2]. This work involved measuring the vertical stress under a square footing of $0.15 \mathrm{~m} \times$ $0.15 \mathrm{~m}$ acting on a sample of sandy soil with $0.70 \mathrm{~m} \times 0.70 \mathrm{~m}$ $\times 0.70 \mathrm{~m}$, as shown in Fig. (2). The main stages of the FE example model are summarized in Table $\mathbf{1}$.

In the study mentioned [2], the main purpose of the FE mo-

\footnotetext{
* Address correspondence to this author at the Department of Civil Engineering, Mansoura Higher Institute for Engineering and Technology, Mansoura, Egypt; Tel: 01000001815; E-mail: ahmed_elgamel@hotmail.com
}

dels was to measure the vertical stress occurring under the centerline of the uniformly loaded square footing at specific depths. An additional goal after verifying the model was to use it to investigate the expected settlement trough.

\section{INITIAL STAGE OF MODELING}

\subsection{Purpose of Model}

The first step in establishing an FE model is to identify the purpose of the analysis. The model may be intended for (i) structural failure prediction, (ii) deformation determination, (iii) consolidation analysis, or (iv) water flow analysis, among others. Each of the above stage needs a specific approach; therefore, the aim must be defined at the outset.

\subsection{Data Collection}

After defining the model's primary purpose, an extensive search is required for information sources and site investigations. The required information comes in the following four main categories.

\subsubsection{Ground Geotechnical Information}

The ground investigation must be planned carefully to get the information needed to represent the ground materials in the FE model accurately. The site conditions are defined mainly from characterization tests and borehole sampling descriptions. Depending on the purpose of the analysis, the essential geotechnical parameter values can be determined from 
specialized parameter testing.

In the selected case study [2], the tested soil stratum was defined according to the Unified Soil Classification System. The tested sand was poorly graded sand (SP); the index properties are listed in Table 2. The geotechnical parameters take the measured values, except for the cohesion, which was changed from zero to $1.00 \mathrm{kN} / \mathrm{m}^{2}$ to avoid numerical error calculations.

Table 1. Summary of main steps of illustrative FE example model.

\begin{tabular}{|c|c|c|c|}
\hline S.No & Stage & Sub-Stages & Description \\
\hline \multirow[t]{2}{*}{1} & \multirow[t]{2}{*}{ Initial } & Purpose & $\begin{array}{l}\text { Measure vertical stress occurring at the centerline of uniformly loaded square footing at specific } \\
\text { depths and determine the settlement trough }\end{array}$ \\
\hline & & Data collection & Collect geotechnical information (Table 2) \\
\hline \multirow{2}{*}{2} & \multirow{2}{*}{$\begin{array}{l}\text { Model } \\
\text { establishment }\end{array}$} & Geometry plotting & Geometries (Table $\mathbf{3}$ ) and graphs (Figs. 3 and $\mathbf{4}$ ) of three FE models \\
\hline & & Model boundaries & Boundary dimensions of the three FE models (Fig. 4) \\
\hline \multirow{4}{*}{3} & \multirow{4}{*}{ Model development } & Meshing & A graded mesh (Fig. 7) \\
\hline & & Constitutive models & Choose the Mohr-Coulomb and linear elastic constitutive models (Figs. 3 and 4) \\
\hline & & Construction stages & $\begin{array}{l}\text { In the initial stage, } K \text { analysis is used. In the construction phases, plastic analysis is used. No water } \\
\text { pressure analysis was performed. }\end{array}$ \\
\hline & & Tolerance error & Force criterion used as a stopping criterion with a tolerance of 0.01 \\
\hline \multirow[b]{3}{*}{4} & \multirow[b]{3}{*}{ Results } & Check sensitivity & Boundary conditions checked with almost zero deformation on the edges \\
\hline & & Check validity & Results validated using the laboratory results of Keskin et al. (2008) \\
\hline & & Check accuracy & $\begin{array}{c}\text { Calculated errors in final results: } \\
\text { - Axisymmetric: }(25.29 \pm 2) \% \\
\text { - Plain strain: }(90.40 \pm 22) \% \\
\text { • 3D: }(11.01 \pm 2) \%\end{array}$ \\
\hline
\end{tabular}

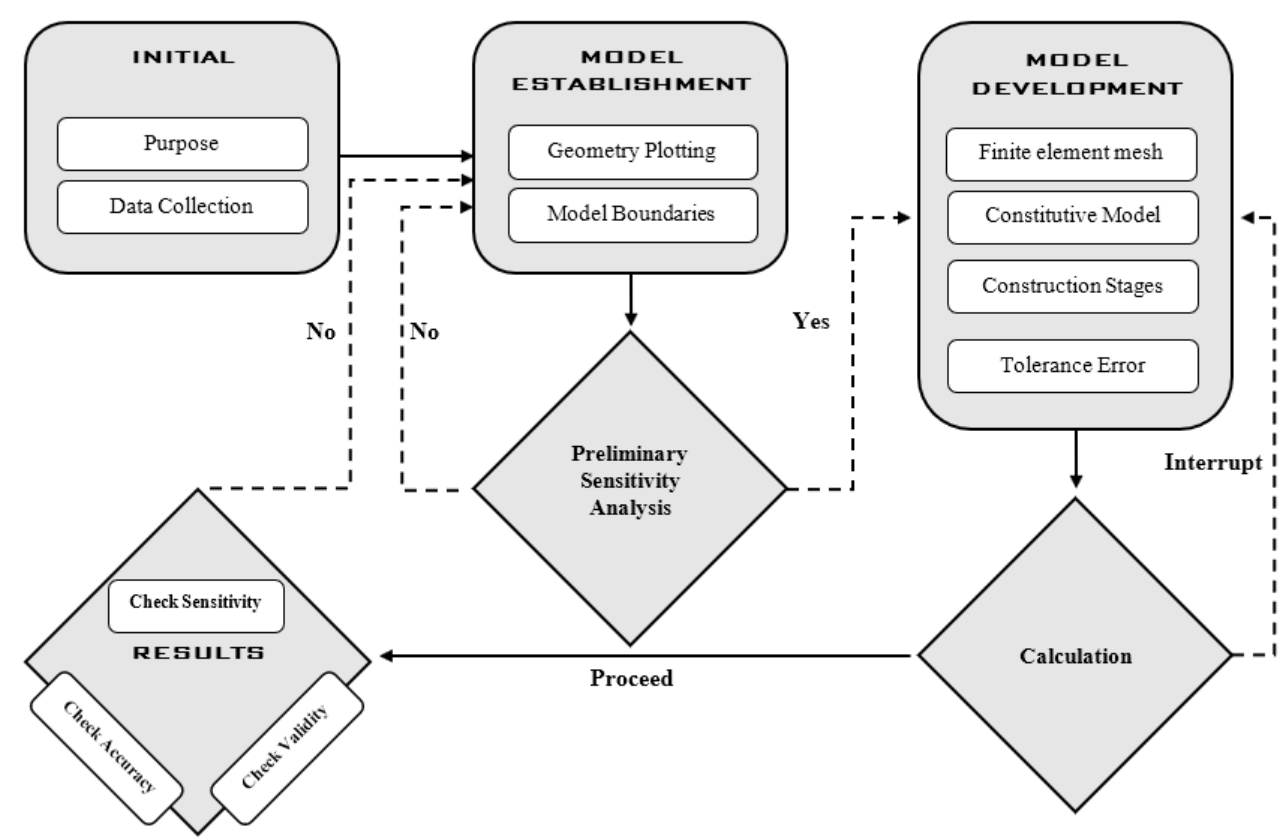

Fig (1). Main stages of geotechnical finite-element (FE) modeling.

Table 2. Index properties of sand.

\begin{tabular}{|c|c|c|}
\hline Parameter & Value & Unit \\
\hline Relative density $\left(D_{r}\right)$ & 65.00 & $\%$ \\
\hline Dry unit weight $\left(\gamma_{d r y}\right)$ & 17.10 & $\mathrm{kN} / \mathrm{m}^{3}$ \\
\hline Young's modulus $(E)$ & 28000 & $\mathrm{kN} / \mathrm{m}^{2}$ \\
\hline
\end{tabular}


(Table 2) contd.....

\begin{tabular}{|c|c|c|}
\hline Parameter & Value \\
\hline Cohesion $(c)$ & $\mathrm{kN} / \mathrm{m}^{2}$ & 0.0 \\
\hline Internal friction angle $(\varphi)$ & 41.00 \\
\hline Dilatation angle $(\psi)$ & 11.00 & 0 \\
\hline Poisson's ratio $(v)$ & 0.20 \\
\hline
\end{tabular}
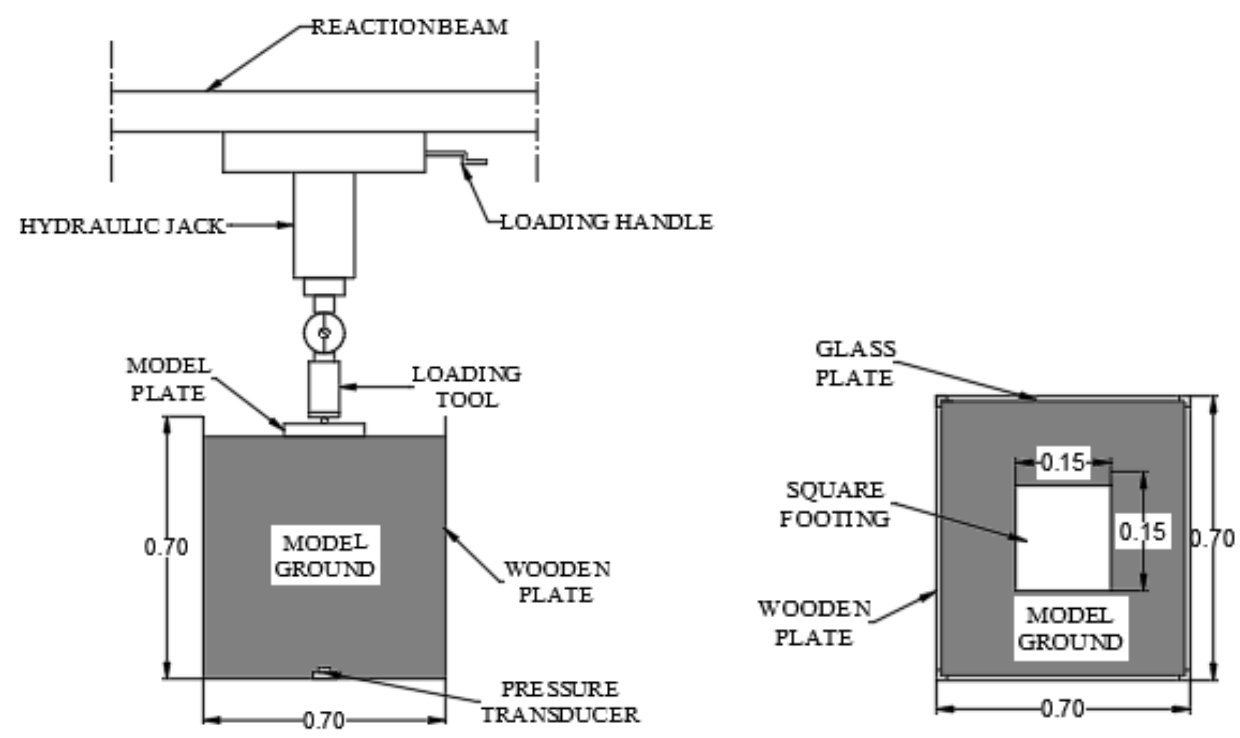

Fig. (2). Schematic of the case study.

Table 3. Different geometry plotting techniques for FE model.

\begin{tabular}{|c|c|c|c|}
\hline Technique & 2D Plane Strain & 2D Axisymmetric & 3D \\
\hline Definition & $\begin{array}{l}\text { To analyze a vertical plane section through the } \\
\text { site. } \\
\text { In the third dimension (i.e., perpendicular to the } \\
\text { plane), strain and displacement are assumed to be } \\
\text { zero. }\end{array}$ & $\begin{array}{l}\text { Except that one vertical side of the plane } \\
\text { (often the left-hand side) is the axis around } \\
\text { which the site exhibits rotational symmetry, } \\
\text { analysis of plane, i.e., vertical section across } \\
\text { the site, must be conducted. The radius from } \\
\text { the axis of symmetry is the horizontal axis, } \\
\text { and the strain perpendicular to the plane and } \\
\text { in the circumferential or hoop direction is } \\
\text { considered to be zero. }\end{array}$ & $\begin{array}{l}\text { Analysis using three dimensions } \\
\text { considering the full-scale model }\end{array}$ \\
\hline Applications & $\begin{array}{c}\text { Suitable to sites with a uniform cross-section, } \\
\text { including ground conditions (ii) stress } \\
\text { state/loading for a sufficiently long straight } \\
\text { dimension for virtually zero strain to be expected } \\
\text { in the long dimension (e.g., straight tunnels, } \\
\text { embankments, long excavations, strip } \\
\text { foundations). }\end{array}$ & $\begin{array}{l}\text { Suitable for sites with a vertical structure in } \\
\text { the ground with a uniform radial cross- } \\
\text { section (e.g., vertical shaft, circular } \\
\text { cofferdam, single vertical pile, circular } \\
\text { spread foundation) and vertical loading that } \\
\text { is uniform around the central axis. }\end{array}$ & $\begin{array}{l}\text { Suited to all cases and site } \\
\text { conditions }\end{array}$ \\
\hline Limitations & $\begin{array}{l}\text { Sites with pile foundations, ground anchors, or } \\
\text { similar structural geometries are not suitable. }\end{array}$ & $\begin{array}{l}\text { Suited to structures with a radial cross- } \\
\text { section only }\end{array}$ & $\begin{array}{c}\text { Time-consuming and requires } \\
\text { considerable computational power }\end{array}$ \\
\hline $\begin{array}{c}\text { Model } \\
\text { configuration }\end{array}$ & it & 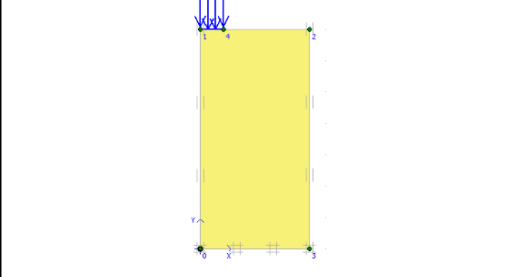 & \\
\hline
\end{tabular}




\subsubsection{Geological Information}

Data from geological surveys are crucial for determining the values of specific ground parameters, especially regarding rock mechanics. However, no geological information is required in the present case.

\subsubsection{Historical Information and Construction Stages}

The stress history and stress path have considerable effects on the behavior of soil and rocks. The historical construction stages up to the present day must be simulated in the FE model if the simulation of the stress path and current stress state is accurate.

\subsubsection{Existing Structures and Infrastructure}

If the site already has structures or infrastructure, then preferably the details of the actual geotechnical structures must be obtained.

\section{MODEL ESTABLISHMENT}

\subsection{Geometry Plotting}

Three FE models are established and plotted, namely (i) a 2D plane strain model, (ii) a 2D axisymmetric model, and (iii) a 3D model, of which the 3D model is the most realistic for the square loading plate. The $2 \mathrm{D}$ axisymmetric model treats the footing as circular rather than square, giving an acceptable error in the desired results. The 2D plane strain model is the least suited to the present geometry, treating the square loading plate as rectangular with dimensions of $0.15 \mathrm{~mm} \times 1.00 \mathrm{~mm}$, exhibiting a significant error in the results. Table 3 describes the different techniques of geometry plotting. The results of the case study are described graphically in Figs. (3 and 4). Fig. (3) shows the vertical stress versus depth, and Fig. (4) shows the settlement trough in a plot of settlement versus horizontal distance from the center of the footing.

\subsection{Model Boundaries}

\subsubsection{Location}

The FE mesh must be fixed in space to determine the displacement to solve the global stiffness equation. The fixedness is applied at the model's boundaries; however, there are often no defined boundaries for the FE model because the ground extends indefinitely. As a result, some judgment is necessary when choosing where the model borders should be placed. The borders should not be set too near the region of interest since this would be impractical and result in a strong boundary effect. The fixedness imposed at the boundaries would begin to impact the critical outputs.

For the selected case study, the dimensions of the laboratory model provide clearly defined boundaries, as shown in Fig. (5). The boundaries should not be placed too close to the area of interest because that would be unrealistic and introduce a significant boundary effect, i.e., the fixedness imposed at the boundaries would start to influence the key outputs. The boundaries affect the FE meshing, and a sensitivity analysis is crucial for determining the appropriate boundaries. Fig. (6) shows the expected boundaries for different cases.

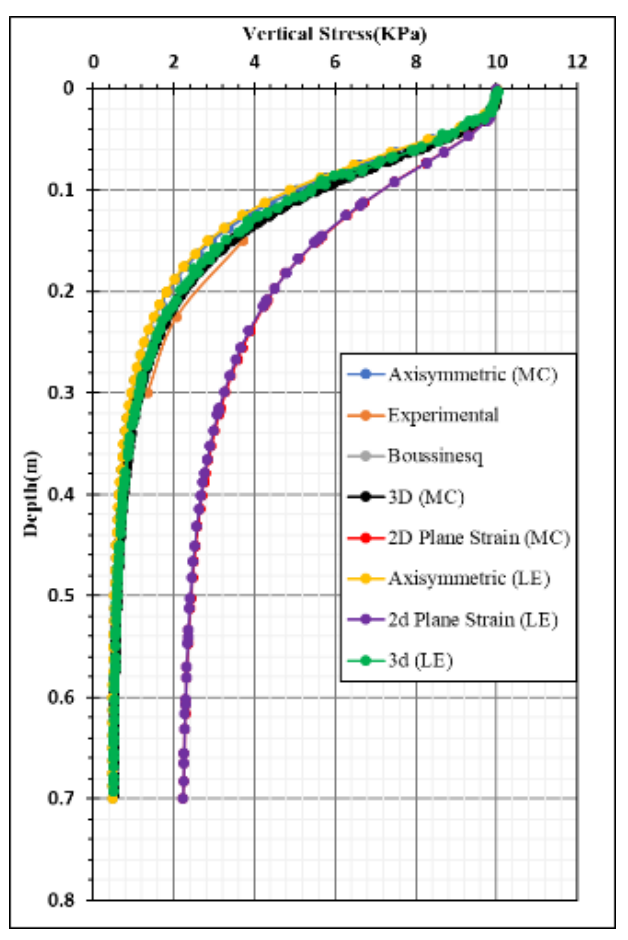

Fig. (3). Vertical stress versus depth (case study). 


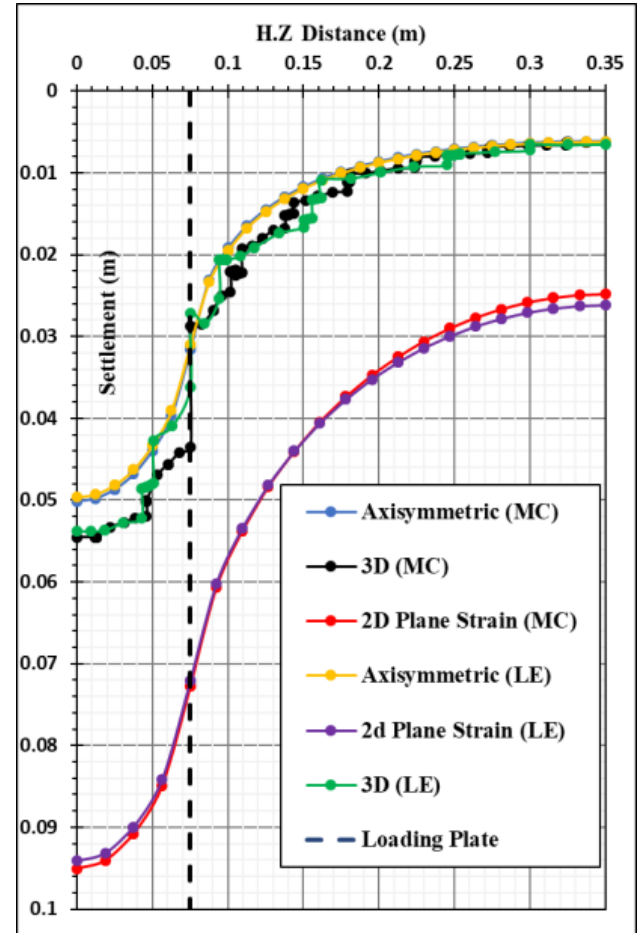

Fig. (4). Settlement trough versus horizontal distance (case study).

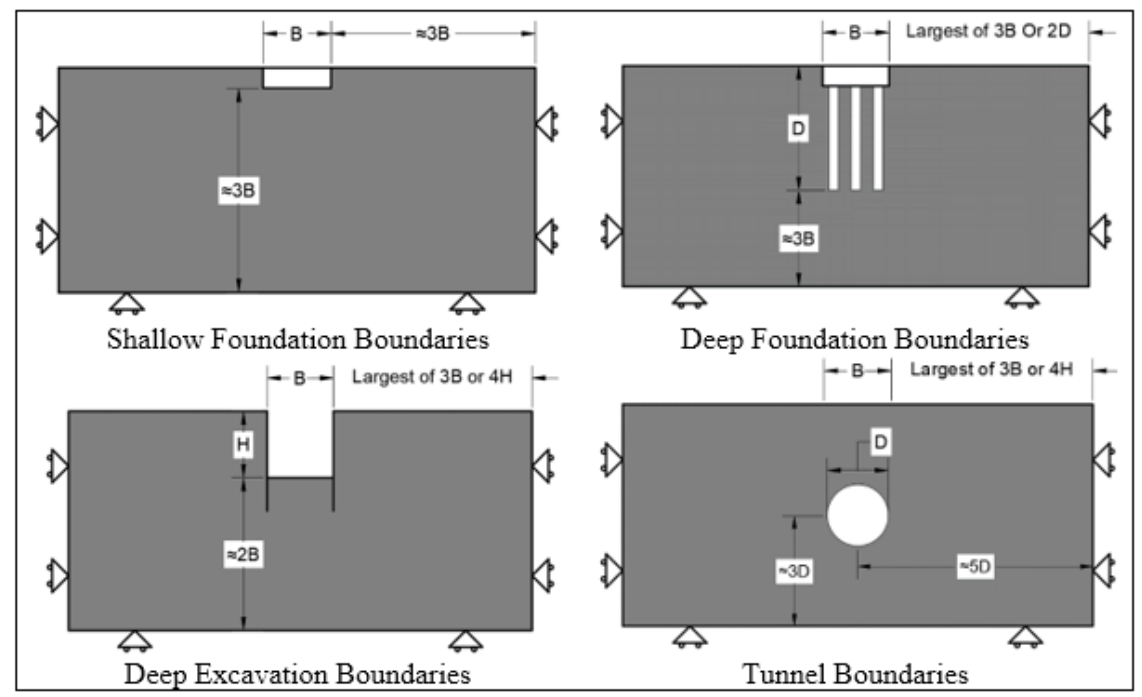

Fig (5). Appropriate first-guess FE mesh boundary locations for different case studies.

\subsubsection{Types of Fixedness at Model Boundaries}

The standard types of fixedness applied at the model boundaries are (i) zero displacement in all directions at the bottom boundary and (ii) zero displacement on the vertical sides in the horizontal direction perpendicular to all those boundaries, including on axes of symmetry. The top surface has no fixedness imposed.

The nature of the fixedness is minor at faraway model borders that are sufficiently far from the region of interest. Indeed, varying such fixedness provides a way to assess the sensitivity of the essential outputs to boundary effects.

\section{MODEL DEVELOPMENT}

\subsection{Meshing}

After the model's geometry has been created, it is replaced with an equal FE mesh that uses continuum elements to represent the ground. Elements generate the mesh based on the degree of precision necessary in the model (a higher number of minor elements gives great precision). The nodes, which are discrete places where the significant unknowns (displacement or excess pore pressure) are computed, link the components. Shape functions or interpolation functions are used to 
interpolate nodal displacements for all points in each element to yield secondary or derived quantities of strains or strain rates, as well as stresses or stress rates. The stresses and strains are computed at Gauss, stress, or integration points located across the element.

\subsubsection{Types of Element}

Higher-order elements contain more nodes and Gauss points, resulting in more precise stress computations, especially stiff behavior. In geotechnical FE analysis, linear and cubic strain element types are widely employed. Linear strain elements are quick to compute and are adequate for most deformation studies if there are enough of them. They might not be appropriate for 2D axisymmetric models, and they might

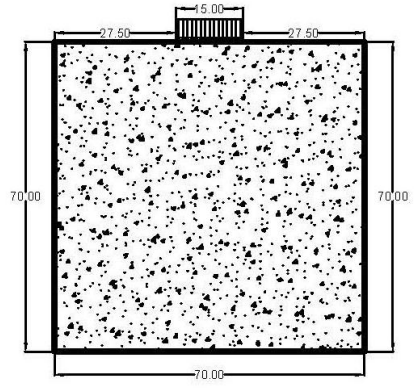

2D Plane Strain Model Boundaries

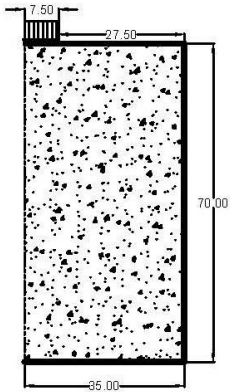

2D Axisymmetric Model Boundaries

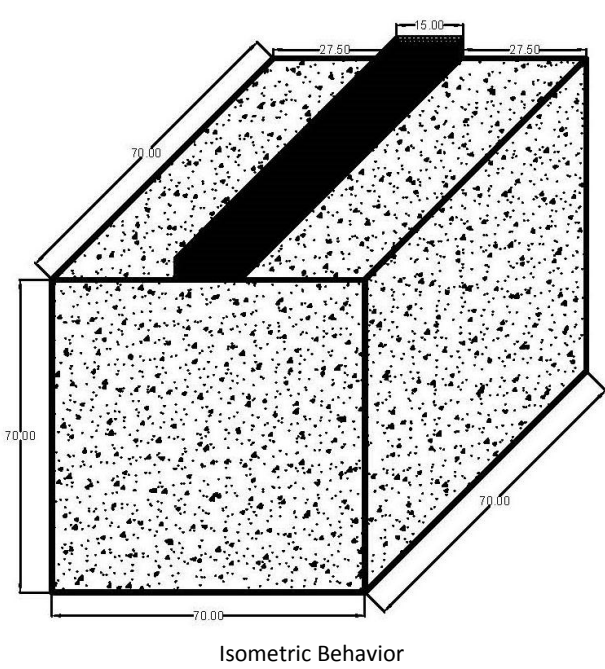

overestimate failure loads in all models (although this tendency is reduced by using reduced integration).

To forecast failure situations in general, and in particular, for axisymmetric models, cubic strain elements (e.g., a 15-node triangle) are favored despite the associated slower computation. When analyzing groundwater flow, lower-order elements are appropriate or even preferred in some programs. The triangular (2D) and tetrahedral (3D) elements have the advantages of I fitting into complex forms more readily, (ii) being compatible with automatic mesh generators, and (iii) being less prone to distortion mistakes. Element definition begins by assuming a displacement field caused by a shape function such as a onedimensional, 2D, or 3D element. Table 4 shows the hierarchy of element categories.
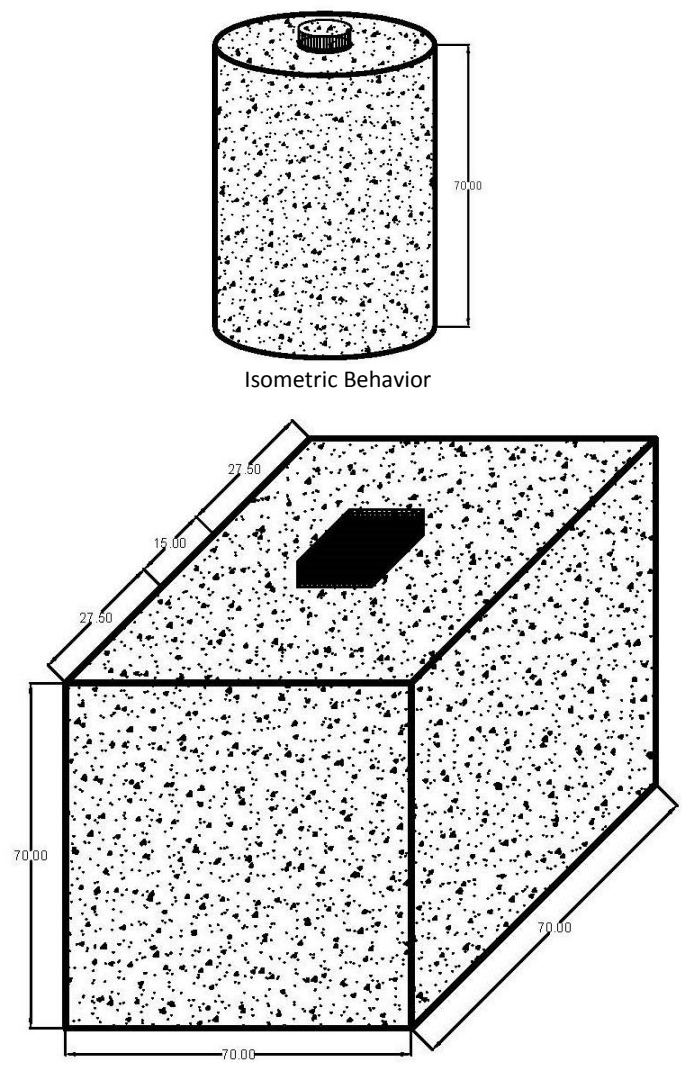

3D Models Boundaries

Fig (6). Appropriate first-guess FE mesh boundary locations for the proposed case study.

Table 4. Types of elements arranged in a hierarchy.

\begin{tabular}{|c|c|c|c|}
\hline \multirow{2}{*}{ Shape Function } & \multicolumn{2}{|c|}{ Variation Across Element } & \multirow{2}{*}{ Elements for Continua } \\
\cline { 2 - 3 } & Displacement & Strain & TRI3, QUAD4, TET4, HEX8 \\
\hline First-order & Linear & Constant & TRI6, QUAD9, TET10, HEX20 \\
\hline Second-order & Quadratic & Linear & TRI10, QUAD16, \\
\hline Third-order & Cubic & Quadratic & TRI5 \\
\hline Fourth-order & Quartic & Cubic & \\
\hline
\end{tabular}

TRI = triangle, $\mathrm{QUAD}=$ quadrilateral, $\mathrm{TET}=$ tetrahedron, $\mathrm{HEX}=$ hexahedron; the associated number is the number of nodes per element. 


\subsubsection{Interface Elements}

Interface elements are used to create a relative displacement between elements in the normal and shear directions. There are two types of interfaces, namely a line interface and a plane interface. A line interface is used between two planar elements (plane stress or plane strain) or between planar elements and structural elements (beam and truss elements); it consists of either 4- or 6-node elements. A plane interface is used between two solid elements or between solid and planar elements; it consists of either 6- or 12-node elements for triangular elements and 8- or 16-node elements for rectangular elements. Overall, increasing the number of nodes in a specific element captures more of the actual soil behavior. The only constraints are the available computing power and analysis time.

\subsubsection{Mesh Size}

The most precise mesh would be one with small elements all over, but this would take a long time to compute. A good FE mesh is graded, with minor components just where needed and more significant elements far away from the area of concern, where stresses and strains are more evenly distributed. Fig. (7) shows the mesh used in the present case. Zone 1 is the area of interest with the minor elements, zone 2 is farther away with intermediate-size elements, and zone 3 is the farthest away with the most considerable elements. Such a mesh offers faster computation with no significant loss of accuracy.

Because of the larger number of nodes per element, meshes made with higher-order elements can be coarser. Higher-order elements heavily influence the prediction of collapse loads, and meshes make those elements progressively finer until collapse loads appear unaffected by mesh geometry. The displacement and stress distributions computed by the interpolation functions are only reliable if the element shapes are not altered significantly.

Due to the inability of automatic mesh generators to control such distortion, it must be verified manually. If the sides of each element are about the same length, distortion is less of an issue for triangular and tetrahedral elements.

\subsection{Material Constitutive Models}

Table 5 describes the most common constitutive models used to represent ground behavior. In the present case study, the results obtained with the linear elastic (LE) and MohrCoulomb (MC) constitutive models are plotted in (Figs. 3 and 4), showing minor differences.

\subsection{Construction}

\subsubsection{Initial Stresses}

In terms of FE modeling, any nonlinear constitutive model's predicted stress-strain behavior is dependent on the current stress state. When material properties are dependent on whether the material is above or below the groundwater level, the groundwater level should coincide with element boundaries. Once the pore pressure profile and ground densities are known, the effective vertical stress is relatively simple to calculate; however, the effective horizontal stress must be calculated from the vertical stress using the stress ratio $K$.

Many approximate equations are available to help validate measured values or estimate K0, such as Jaky's equation [11] used for customarily consolidated soils. For overconsolidated soils, other more approximate equations have been proposed for estimating $K$ [12]. As shown in Fig. (8), there are two methods for determining the initial stress in a FE analysis. Direct specification ( $K$ method) is used for homogeneous stress profiles with a horizontal ground surface, strata, and groundwater levels. Because the FE analysis achieves vertical equilibrium while the horizontal stress is based solely on the specified $K$ or horizontal stress values, the equilibrium may not be achieved. Minor equilibrium errors may be acceptable due to a slight inclination in the layers or ground surface. In this case, a plastic nil-step should be performed after the initial stress is established.

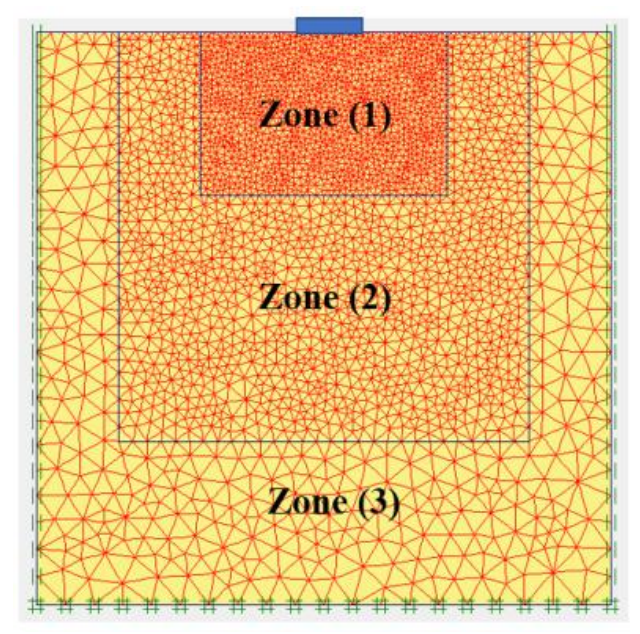

Fig (7). Mesh gradation zones for case study. 


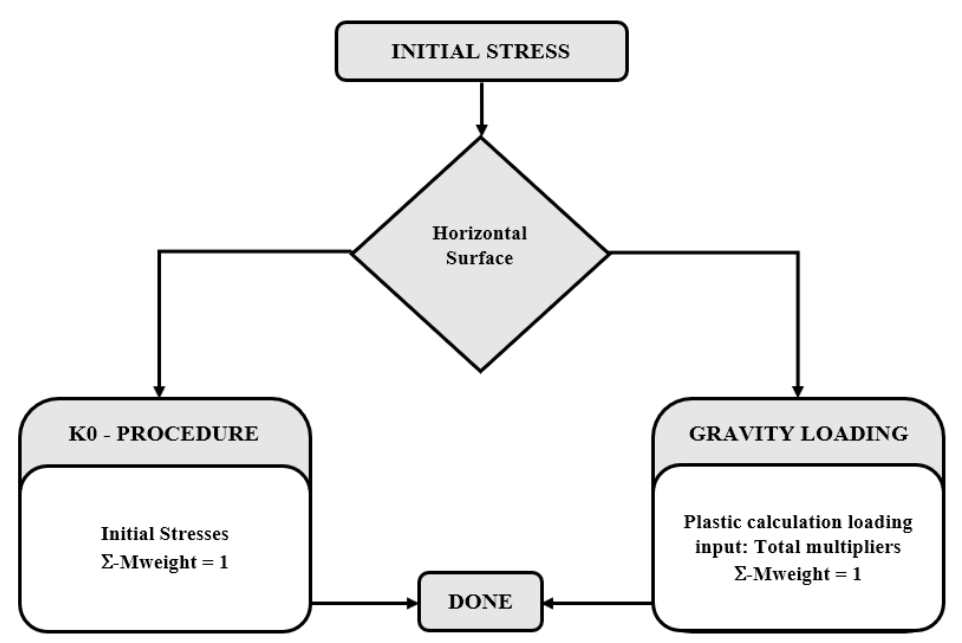

Fig (8). Establishing initial stress in an FE analysis flowchart.

Table 5. Description of material constitutive models.

\begin{tabular}{|c|c|c|c|c|}
\hline Model & Definition & Parameters & Applications & Limitations \\
\hline $\begin{array}{l}\text { Mohr-Coulomb } \\
\text { (MC) }\end{array}$ & $\begin{array}{l}\text { A well-known and straightforward linear } \\
\text { elastic-plastic model that offers first } \\
\text { approximation of soil behavior. The linear } \\
\text { elastic part of the MC model is based on } \\
\text { Hooke's law of isotropic elasticity. The } \\
\text { perfectly plastic part is based on the MC } \\
\text { failure criterion, formulated in a non- } \\
\text { associated plasticity framework. }\end{array}$ & $\begin{array}{c}E\left[\mathrm{kN} / \mathrm{m}^{2}\right]: \text { Young's } \\
\text { modulus } \\
v_{u r}: \text { Poisson's ratio } \\
c\left[\mathrm{kN} / \mathrm{m}^{2}\right]: \text { cohesion } \\
\varphi\left[^{\circ}\right]: \text { friction angle } \\
\Psi\left[^{\circ}\right]: \text { dilatancy angle }\end{array}$ & $\begin{array}{l}\cdot \text { Used to model soil } \\
\text { behavior in general } \\
\text { • Failure behavior is } \\
\text { generally well captured (at } \\
\text { least for drained conditions) } \\
\text {-Can provide the first } \\
\text { estimate of deformation }\end{array}$ & $\begin{array}{l}\text { •Has limited ability to model } \\
\text { deformation behavior } \\
\text { accurately before failure, } \\
\text { especially when stress level } \\
\text { changes significantly or } \\
\text { multiple different stress paths } \\
\text { are followed } \\
\text {-When used for excavation } \\
\text { and retaining-wall problems, } \\
\text { it generally leads to a massive } \\
\text { pit bottom heave, which may } \\
\text { cause an unrealistic uplift of } \\
\text { the retaining wall } \\
\text {-In tunneling problems, its use } \\
\text { produces a settlement trough } \\
\text { that is generally too wide }\end{array}$ \\
\hline $\begin{array}{c}\text { Linear Elastic } \\
\text { (LE) }\end{array}$ & $\begin{array}{l}\text { It obeys Hooke's law of linear relation } \\
\text { between stress and strain. Materials } \\
\text { modeled using the LE model are deformed } \\
\text { elastically throughout the analysis, which } \\
\text { means that they return to their initial state } \\
\text { upon unloading. }\end{array}$ & $\begin{array}{c}E\left[\mathrm{kN} / \mathrm{m}^{2}\right]: \text { Young's } \\
\text { modulus } \\
v_{u r}: \text { Poisson's ratio }\end{array}$ & $\begin{array}{l}\text { Used to model stiff } \\
\text { materials in soil (e.g., thick } \\
\text { concrete walls or plates, } \\
\text { rock layers) or far-field } \\
\text { areas where plasticity plays } \\
\text { no significant role. }\end{array}$ & $\begin{array}{c}\text {-Not suitable for modeling } \\
\text { soil in general } \\
\text {-Cannot estimate failure } \\
\text { behavior }\end{array}$ \\
\hline $\begin{array}{l}\text { Hardening Soil } \\
\text { (HS) }\end{array}$ & $\begin{array}{l}\text { A true second-order model for soils in } \\
\text { general (soft soils and harder ones) for any } \\
\text { application. Involves friction hardening to } \\
\text { model plastic shear strain in deviatoric } \\
\text { loading and cap hardening to model plastic } \\
\text { volumetric strain in primary compression. }\end{array}$ & \begin{tabular}{|c|}
$c\left[\mathrm{kN} / \mathrm{m}^{2}\right]:$ cohesion \\
$\varphi\left[{ }^{\circ}\right]:$ friction angle \\
$\Psi\left[^{\circ}\right]:$ dilatancy angle \\
$S_{t}\left[\mathrm{kN} / \mathrm{m}^{2}\right]:$ tension cut- \\
off and tensile strength \\
$E_{50}{ }^{\text {ref }}\left[\mathrm{kN} / \mathrm{m}^{2}\right]:$ secant \\
stiffness in standard \\
drained triaxial test \\
$E_{\text {Oed }}{ }^{\text {ref }}\left[\mathrm{kN} / \mathrm{m}^{2}\right]:$ tangent \\
stiffness for primary \\
oedometer loading \\
$E_{\text {ur }}{ }^{\text {ref }}\left[\mathrm{kN} / \mathrm{m}^{2}\right]:$ \\
unloading $/$ reloading \\
stiffness \\
$m$ : Power of stress-level \\
dependency on stiffness
\end{tabular} & $\begin{array}{c}\text {-Accurate for problems } \\
\text { involving a reduction of } \\
\text { mean effective stress and, at } \\
\text { the same time, mobilization } \\
\text { of shear strength. Such } \\
\text { situations occur in } \\
\text { excavations (retaining-wall } \\
\text { problems) and tunnel } \\
\text { construction projects } \\
\text {-It can be used to predict } \\
\text { displacement and failure } \\
\text { accurately for general types } \\
\text { of soil in various } \\
\text { geotechnical applications }\end{array}$ & $\begin{array}{l}\text {-It does not include } \\
\text { anisotropic strength or } \\
\text { stiffness, nor time-dependent } \\
\text { behavior (creep) } \\
\text { •Has limited ability for } \\
\text { dynamic applications }\end{array}$ \\
\hline
\end{tabular}




\begin{tabular}{|c|c|c|c|c|}
\hline Model & Definition & Parameters & Applications & Limitations \\
\hline $\begin{array}{l}\text { Hoek-Brown } \\
\text { (HB) }\end{array}$ & $\begin{array}{l}\text { An empirically derived relationship is used } \\
\text { to describe a nonlinear increase in peak } \\
\text { strength of isotropic rock with increasing } \\
\text { confining stress. It follows a nonlinear, } \\
\text { parabolic form that distinguishes it from the } \\
\text { linear MC failure criterion. Includes } \\
\text { companion procedures developed to provide } \\
\text { a practical means to estimate rock mass } \\
\text { strength from laboratory test values and } \\
\text { field observations. }\end{array}$ & \begin{tabular}{|c|}
$E_{r m}\left[\mathrm{kN} / \mathrm{m}^{2}\right]$ : rock-mass \\
Young's modulus \\
$v:$ Poisson's ratio \\
$S_{c i}\left[\mathrm{kN} / \mathrm{m}^{2}\right]$ : uniaxial \\
compressive strength of \\
intact rock \\
$m_{i}:$ intact-rock \\
parameter \\
$G S I:$ geological \\
strength index \\
$\Psi_{\max }\left[{ }^{\circ}\right]:$ dilatancy angle \\
$\left(\right.$ at $\left.s_{3}^{\prime}=0\right)$ \\
$S_{\Psi}\left[\mathrm{kN} / \mathrm{m}^{2}\right]:$ an absolute \\
value of confining \\
pressure $s_{3}^{\prime}$ at which \\
$\Psi_{=}=0$
\end{tabular} & $\begin{array}{l}\text { - Nonlinear in form (in the } \\
\text { meridian plane), which } \\
\text { agrees with experimental } \\
\text { data over a range of } \\
\text { confining stress } \\
\text {-Developed through an } \\
\text { extensive evaluation of } \\
\text { laboratory test data covering } \\
\text { a wide range of intact rocks } \\
\text {-Provides a straightforward } \\
\text { empirical means to estimate } \\
\text { rock-mass properties }\end{array}$ & $\begin{array}{c}\text { - Limitations documented in } \\
\text { detailed discussions on the } \\
\text { simplifying assumptions made } \\
\text { in the derivation of the HB } \\
\text { criterion [3 - 5] } \\
\text { - One of the most important of } \\
\text { these is the independence of } \\
\text { the HB criterion from the } \\
\text { intermediate principal stress } s_{2} \\
\text { - [3] justified this by pointing } \\
\text { to triaxial extension and } \\
\text { compression tests by Walsh } \\
\text { and [6] that showed no } \\
\text { significant variation between } \\
\text { results when } s_{2}=s_{3} \text { and } s_{2}=s_{1} \text {. } \\
\text { Brace concluded that } s_{2} \text { had a } \\
\text { negligible influence on failure } \\
\text { - True triaxial testing by others } \\
\text { [7] shows that a more } \\
\text { pronounced influence of } s_{2} \text { is } \\
\text { discounted as involving } \\
\text { brittle/ductile transitions in the } \\
\text { failure process }\end{array}$ \\
\hline $\begin{array}{l}\text { Modified Cam } \\
\text { Clay (MCC) }\end{array}$ & $\begin{array}{l}\text { An elastic-plastic strain-hardening model } \\
\text { where the nonlinear behavior is modeled } \\
\text { using hardening plasticity. It is based on } \\
\text { critical-state theory and the basic } \\
\text { assumption that there is a logarithmic } \\
\text { relationship between mean effective stress } \\
p^{\prime} \text { and void ratio } e \text {. Virgin compression and } \\
\text { recompression lines are linear in } e-\ln p^{\prime} \\
\text { space, which is most realistic for near- } \\
\text { normally consolidated clays. Only linear } \\
\text { elastic behavior is modeled before yielding } \\
\text { and may result in unreasonable values of } v \\
\text { due to log-linear compression lines. }\end{array}$ & $\begin{array}{c}v_{u}: \text { Poisson's ratio } \\
K: \text { Cam-clay swelling } \\
\text { index } \\
\lambda: \text { Cam-clay } \\
\text { compression index } \\
M: \text { tangent of the } \\
\text { critical state line } \\
e_{\text {int }}: \text { initial void ratio }\end{array}$ & $\begin{array}{c}\text { •It is more suitable for } \\
\text { describing deformation than } \\
\text { failure, especially for } \\
\text { normally consolidated soft } \\
\text { soils } \\
\text { •It also performs best in } \\
\text { applications involving } \\
\text { loading conditions such as } \\
\text { embankments or } \\
\text { foundations. In the case of } \\
\text { primary undrained } \\
\text { deviatoric loading of soft } \\
\text { soils, the MCC model } \\
\text { predicts more realistic } \\
\text { undrained shear strength } \\
\text { compared to the MC model }\end{array}$ & $\begin{array}{l}\text { • Yu }[8,9] \text { identified the } \\
\text { limitations of the MCC model. } \\
\text { The yield surfaces adopted in } \\
\text { many critical-state models } \\
\text { significantly overestimate } \\
\text { failure stresses on the 'dry } \\
\text { side' } \\
\text {-These models assumed an } \\
\text { associated flow rule and } \\
\text { therefore could not predict an } \\
\text { essential feature of behavior } \\
\text { that is commonly observed in } \\
\text { undrained tests on loose sand } \\
\text { and normally consolidated } \\
\text { undisturbed clays, namely a } \\
\text { peak in the deviatoric stress } \\
\text { before the critical state is } \\
\text { approached } \\
\text {-The critical state has been } \\
\text { much less successful for } \\
\text { modeling granular materials } \\
\text { because of its inability to } \\
\text { predict observed softening and } \\
\text { dilatancy of dense sands and } \\
\text { the undrained response of } \\
\text { very loose sands. } \\
\text { • Gens and Potts [10] } \\
\text { confirmed the above } \\
\text { limitations. They noted that } \\
\text { the materials modeled by } \\
\text { critical-state models appeared } \\
\text { mostly limited to saturated } \\
\text { clays and silts and that stiff } \\
\text { overconsolidated clays were } \\
\text { generally not modeled with } \\
\text { critical-state formulations. }\end{array}$ \\
\hline
\end{tabular}

For cases with a sloping ground surface but horizontal strata, initial stresses can still be determined by direct specification, which can be done by starting with a horizontal ground surface and then activating or deactivating elements to create the slope in a later analysis stage.

The gravity switch-on is the second method. The initial stress is generated by activating the ground's self-weight and specifying the initial pore pressures in the model in cases of non-homogeneous stress profiles, such as sloping strata.

\subsubsection{Construction Phases}

The FE calculations are divided into several sequential phases corresponding to a loading or construction stage. The types of calculation, loading, and pore-pressure calculation are 
defined in each construction phase. Fig. (9) shows a flowchart of the construction phases.

\subsection{Error Tolerances}

\subsubsection{Convergence Criteria}

The basic equilibrium equation for the $\mathrm{FE}$ analysis is

$$
K \Delta U_{(i+1)}=P_{(n)}-F_{i}
$$

Where, $P$ is the vector of applied loads, $F$ is the vector of internal forces, $\Delta U$ is the vector of nodal displacements, and $K$ is the nonlinear stiffness. For accurate nonlinear analysis, the load $P$ is applied in many load steps $n$. Eq. (1) is normally solved using several iterations $i$, the main aim being to determine $\Delta U$. As shown in Fig. (10), as the number of iterations increases, the load imbalance $P_{(n+1)}-F_{i}$ decreases and the displacement increment also approaches zero $U_{(i)}$ leading to the true solution of the displacement $U_{(i+1)}$.

\subsubsection{Stopping Criteria}

Various stopping criteria can be used to decrease the number of unnecessary iterations, such as the following.

- Absolute energy criterion

$$
\left\|\frac{\Delta U_{i}\left(P_{n}-F_{i}\right)}{\Delta U_{0}\left(P_{n}-F_{0}\right)}\right\|<\text { (specfic energy tolerance) }
$$

- Square-root energy criterion

$$
\frac{\sqrt{\sum_{j=1}^{N}\left(\left(p_{(n), j}-f_{(i), j}\right) \Delta u_{(i), j}\right)^{2}}}{\sqrt{\sum_{j=1}^{N}\left(\left(p_{(n), j}-f_{(0), j}\right) \Delta u_{(0), j}\right)^{2}}}<(\text { specfic energy tolerance) })(3)
$$

For a given load step, these criteria correspond to the solution found when the current state's energy imbalance becomes a small fraction of the initial energy imbalance.

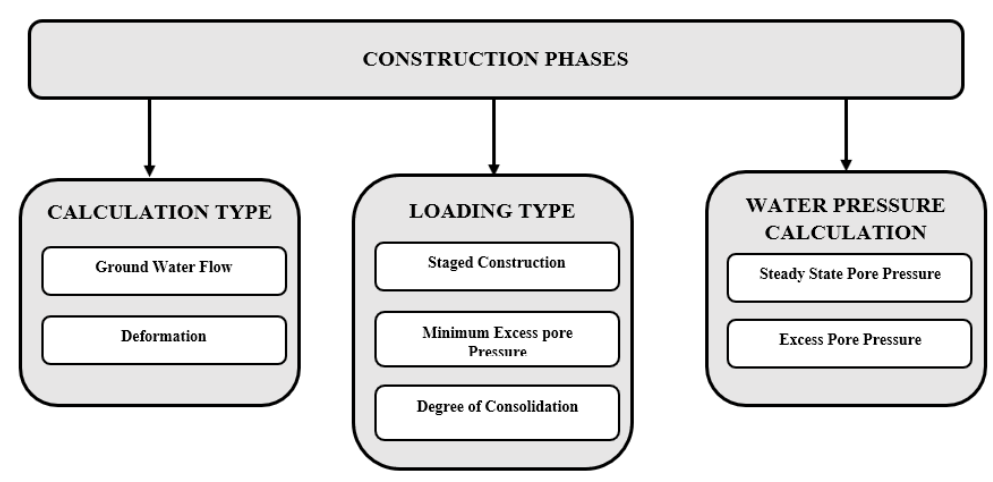

Fig (9). Flowchart of construction phases of FE model.

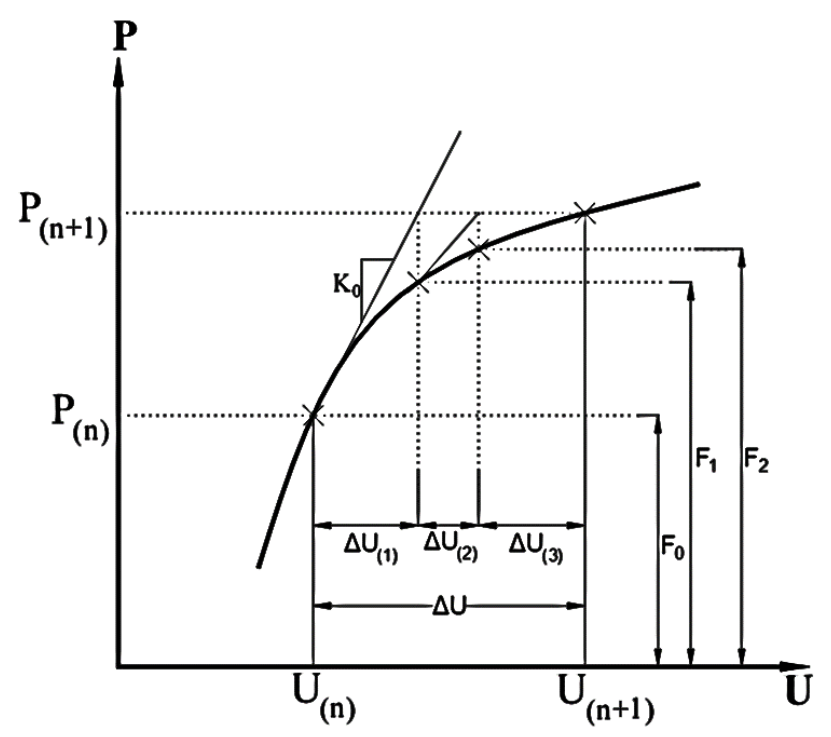

Fig (10). Iterative procedure for determining the behavior for a single degree of freedom under the applied load. 
- Force criterion: stop when the current force imbalance becomes a small fraction of the total applied force.

- Displacement criterion: stop when the current displacement increment becomes a small fraction of the initial displacement.

In the present case study, the force criterion is used as the stopping criterion. The global error tolerance is 0.01 , the maximum number of iterations is 60 , and the number of load steps is 1 .

\section{CONCLUSION}

Recent FE software is inadequate for analyzing vast geotechnical engineering problems. Geotechnical FE analysis is highly dependent on a correct understanding of the soil behavior, parameters, and soil-structure interaction. The flowchart in Fig. (1) describes the main stages of geotechnical FE modeling, along with an illustrative numerical example summarized in Table 1 . The primary phase that significantly impacts the behavior and results of the geotechnical FE model is that the $3 \mathrm{D}$ geometry plotting model acts as the most realistic geometry used with suitable computing power and time consumed. The deformation and stress at the model boundaries tend to be zero. The Mohr-Coulomb criterion is a suitable constitutive model for any soil type to determine preliminary behavior results in order to increase the accuracy of results; a specific constitutive model could be used as described in Table 5. To ensure the success of the FE model, its results must be checked for their validity, sensitivity, and precision.

\section{APPENDIX}

\section{Case Study with Full Details [13]}

\section{Initial Purpose}

The principal aim is to present $3 \mathrm{D}$ numerical analyses based on the FE technique to predict and mitigate the impact of minimum overburden depth for the Nile crossing tunnel. The numerical modeling was developed to simulate soil-tunnel interactions using the commercial 3D FEM program MIDAS/GTSNX powered by TNO-Diana's solver. The general work sequence of GTS is as follows:
A. Ground and Structural Materials
B. Properties of used mesh element
C. Geometry Modeling
i. Create terrain surfaces from geometric data.

ii. Create a tunnel section.

iii.Extrude to generate 3D modeling.

iv. Make a shared face between solids.

v. Create dividing tool surfaces that represent construction stages.

\section{Mesh Generation}

The mesh size must be controlled to get a high-quality mesh with fewer meshes; this can be done quickly using the size control. In the [Auto-Solid] Tab, 'Tetra Mesh' and the 'Hybrid Mesh' can be chosen for any geometry.

\section{E. Boundary Condition}

In 3D model analysis, constraint displacement is applied in $\mathrm{x}$-direction left/right, y-direction front/back, $\mathrm{x}, \mathrm{y}$, and $\mathrm{z}$ directions for the bottom part. GTS automatically recognizes the model boundary and sets the boundary condition.

\section{F. Definition of the static loads}

For static load, define self-weight, construction loads, surcharge.

\section{G. Analysis condition}

Select the analysis type (construction analysis, linear analysis). Then, control analysis and output type in the advance options.

\section{H. Perform Solver}

For Post-processing and Result Evaluation: After the analysis is done, the software automatically switches to postmode (checking results). After the analysis is completed correctly, GTS will organize and provide the post-data result for the design process.

\section{Data Collection}

The study was conducted on the most critical section of the Greater Cairo Metro Line 2 tunnel under the Nile River. Fig. (1A) shows the geological section of the case study.

The details of the bored shield tunnel embedded in the soil are as follows: tunnel diameter $=9.15 \mathrm{~m}$,

lining thickness $=0.40 \mathrm{~m}$, burial depth $(\mathrm{H})=12 \mathrm{~m}$ from the ground surface, segment width $=1.5 \mathrm{~m}$, and grout thickness $=$ $0.15 \mathrm{~m}$.

A local backfilling of the main branch bed is foreseen to ensure a sufficient covering for the shield bored tunnel. Riprap and gravel filters can be modeled as an average weight on the river bed with $60 \mathrm{~m}$ width. 


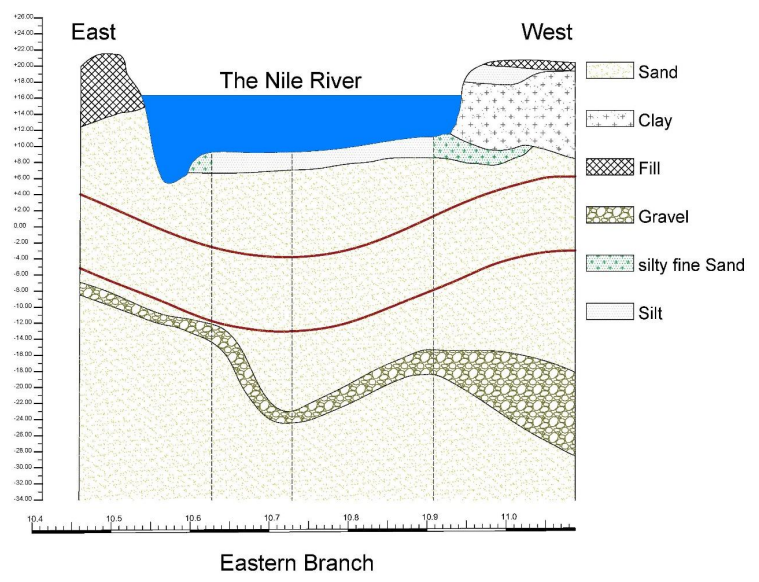

Fig. (1A). Geological section of the case study.

\section{Model Establishment}

\section{Geometry Plotting}

The generation of the geometric model is the foundation of creating a finite element analysis model in GTS.

The dimensions of the overall model in the $x, y$, and $z$ directions are $100.00 \times 105.00 \times 39.00 \mathrm{~m}$ (Fig. $\mathbf{2 A}$ ). The burial depth $(\mathrm{H})$ is assumed to be $5.50 \mathrm{~m}$ from the Nile bed. The water height is $10.00 \mathrm{~m}$ over the bed level.

\section{Model Boundary}

Midas/GTSNX is capable of constraining the model automatically. The nodal DOF along the vertical sides of the model have been constrained in the X-direction. On the other hand, for the front and back, it is constrained in the $\mathrm{Y}$ direction. For bottom nodes, the DOFs of the Z-direction have been constrained with $\mathrm{y}$ and $\mathrm{x}$ directions.

\section{Model Development}

\section{Meshing}

Mesh is generated on the previously created geometry model. For a complex model, it is reasonable to use tetrahedron elements or triangular elements produced by the auto-mesh generation function provided by GTS.

Solid elements were chosen for ground, tunnel, and grout. The essential part of mesh generation is the node connection between adjacent elements to form tetrahedron mesh. Solid elements have three translational degrees of freedom in each element node and no rotational degrees of freedom.

\section{Constitutive Model}

The soil behavior is simulated using the non-associated Mohr-Columb (MC) criteria, the most widely used method for ground materials due to its simplicity and accuracy (Table 1A).

The structure (shield, tunnel, and grout) 'Elastic' model type that does not consider material nonlinearity is used, as shown below (Table 2A).

\section{Construction Analysis}

Active/reactive elements and loads present simulations of the progressive advancement of the TBM. It reflects the change in material properties. It starts from the initial condition of the ground before the commencement of any construction events. The analytical results from the previous stage are accumulated and reanalyzed.

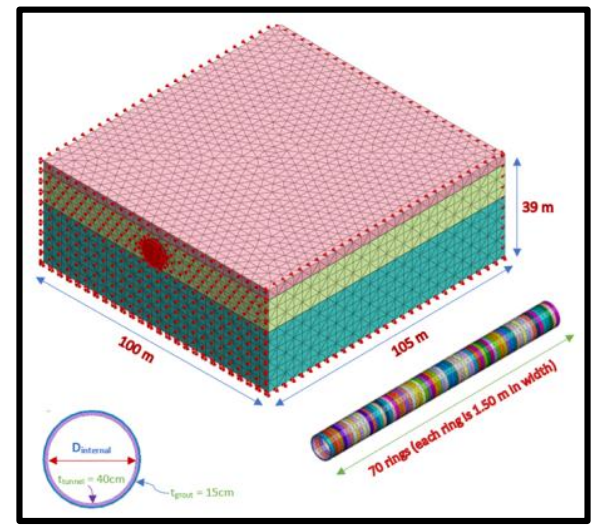

Fig. (2A). Model geometry and boundary. 
Table 1A. Properties of soil materials.

\begin{tabular}{|c|c|c|c|c|c|c|}
\hline Material & $\begin{array}{c}\text { The } \\
\text { Thickness } \\
\text { of Layer } \\
{[\mathbf{m}]}\end{array}$ & $\begin{array}{c}\text { Modulus } \\
\text { of } \\
\text { Elasticity } \\
\mathbf{( E )} \\
{\left[\mathbf{k N} / \mathbf{m}^{2}\right]}\end{array}$ & $\begin{array}{c}\text { Poisson's } \\
\text { Ratio }(\mathbf{v})\end{array}$ & $\begin{array}{c}\text { Unit } \\
\text { Weight } \\
(\boldsymbol{\gamma}) \\
{\left[\mathbf{k N} / \mathbf{m}^{3}\right]}\end{array}$ & $\begin{array}{c}\text { Cohesion } \\
\left(\mathbf{c}_{\mathbf{u}}\right) \\
{\left[\mathbf{k N} / \mathbf{m}^{2}\right]}\end{array}$ & $\begin{array}{c}\text { Friction } \\
\text { Angle } \\
(\boldsymbol{\Phi})[]\end{array}$ \\
\hline $\begin{array}{c}\text { Upper } \\
\text { sand }\end{array}$ & 3.80 & 20000 & 0.30 & 19.00 & 0.00 & 30.00 \\
\hline $\begin{array}{c}\text { Middle } \\
\text { sand }\end{array}$ & 12.30 & 75000 & 0.30 & 20.00 & 0.00 & 36.00 \\
\hline $\begin{array}{c}\text { Lower } \\
\text { sand }\end{array}$ & 23.00 & 90000 & 0.35 & 20.00 & 0.00 & 40.00 \\
\hline
\end{tabular}

Table 2A. A. Properties of concrete lining and grout materials.

\begin{tabular}{|c|c|c|c|}
\hline Materials & $\begin{array}{c}\text { Modulus of } \\
\text { Elasticity (E) } \\
{\left[\mathbf{k N} / \mathbf{m}^{2}\right]}\end{array}$ & $\begin{array}{c}\text { Poisson's } \\
\text { Ratio }(\mathbf{v})\end{array}$ & $\begin{array}{c}\text { Unit Weight } \\
(\gamma)\left[\mathbf{k N} / \mathbf{m}^{3}\right]\end{array}$ \\
\hline $\begin{array}{c}\text { Concrete short } \\
\text { term }\end{array}$ & $2.85 \times 10^{7}$ & 0.20 & 25.00 \\
\hline Concrete long term & $1.516 \times 10^{7}$ & 0.20 & 25.00 \\
\hline Shield & $2.00 \times 10^{8}$ & 0.30 & 75.00 \\
\hline Hard Grout & 50000 & 0.30 & 23.00 \\
\hline Soft Grout & 1000 & 0.30 & 11.00 \\
\hline
\end{tabular}

\section{Construction Loads}

The main construction loads applied in this study are illustrated in Table $\mathbf{3 A}$ and Fig. (3A).

Table 3A. Construction loads.

\begin{tabular}{|c|c|}
\hline Pressure Type & $\begin{array}{c}\text { Value } \\
{\left[\mathbf{k N} / \mathbf{m}^{2}\right]}\end{array}$ \\
\hline Face pressure & 200 \\
\hline Grout pressure & 300 \\
\hline Jacking pressure & 4600 \\
\hline
\end{tabular}

\section{Construction Stages}

A stage-by-stage analysis is employed to simulate the progress of the TBM and the tunnel construction process. The tunnel is divided into 70 rings constructed in 79 stages. The length of the shield is $10.5 \mathrm{~m}$ simulated in the model as a ring with a width of $1.5 \mathrm{~m}$. The face pressure is normal on the excavated soil at the shield face. The soft grout is pumped from the tail of the shield by grouting pressure towards the soil to prevent it from collapsing. The grout results in a compressive force on the segments. The jacking force is rested on the tunnel segment to push the machine to advance.

It is assumed that the grout hardened after two constructed rings, and the grout pressure was simulated considering the soft grout strata. These stages are illustrated in Fig. (4A) and as follows:

- Initial Stage (IS): This stage simulated the initial state of stresses in the terrain before tunneling construction.

- Stage 1 (S1): In this stage, the excavation of the first ring is simulated, and the shield replaces it. The face pressure is released from the start position to be applied to the next ring.

- Stage 2 to 6 (S2:S6): in this stage, the same simulation explained in stage 1 is repeated to excavate the $2^{\text {nd }}$ ring to the sixth ring and replace them with the shield.

- $\quad$ Stage 7 (S7): In this stage, excavation of the seventh ring is simulated and replaced by the shield. With the progression of a machine, the shield's tail exists in the first excavated ring. In the meantime, the first tunnel segments are constructed, and jacking is released.

- $\quad$ Stage 8 (S8): In this stage, excavation of the eighth ring is simulated, and the shield replaces it. With the machine's progression, the shield's tail is released from its position to the second excavated ring, and the shield is present inside the soil with a total length of $10.5 \mathrm{~m}$.

- $\quad$ Stage 9 (S9): In this stage, excavation of the ninth ring is simulated and replaced by the shield. With the progression of the machine, the tail of the shield is released from its position to the third excavated ring.

- Stage 10 (S10): The tenth ring is simulated and replaced by the shield in this stage. With the progression of the machine, the tail of the shield is released from its position to the fourth excavation ring.

- Stage n (Sn): In this stage, excavation of the nth ring is simulated and replaced by the shield. With the progression of the machine, the tail of the shield is released from its position to the next excavated ring. In the meantime, the tunnel segments are constructed, and the jacking is released from its position to be applied on the next. The grout pressure is acted on the perimeter of the segments toward the soil and released before the previous segments, and the hard grout is applied to them. This stage is repeated until all segments are constructed.

\section{Backfilling}

A local backfilling of the main branch bed is foreseen to ensure a sufficient covering for the shield bored tunnel. Riprap and gravel filters can be modeled as an average weight on the river bed with $60 \mathrm{~m}$ width. For the short term, the weight of backfilling is $28.00 \mathrm{kN} / \mathrm{m}^{2}$. For the long-term and exceptional case, the weight of backfilling is $12.00 \mathrm{kN} / \mathrm{m}^{2}$. Fig. (5A) illustrates the backfilling load.

\section{Model Results}

The vertical displacement at the crown of the tunnel during different stages of the tunnel's construction and in-service case were studied. The 3D analysis results (Fig. 6A) showed that the crown vertical displacement value was $18.8 \mathrm{~mm}$. If the cover thickness is less than the theoretical calculation, this is called a critical section. The cover begins approximately one diameter ahead of the tunnel face; the crown vertical displacement value is about $11.1 \mathrm{~mm}$, decreasing by a ratio of $40 \%$. The critical section has a $5.50 \mathrm{~m}$ cover. Two models with/without riprap conduct analyses; in the model with riprap, the maximum heave equals $11.6 \mathrm{~mm}$, but for the model without riprap, the heave is equal to $13.9 \mathrm{~mm}$. 
For the long and short-term combination, the total crown vertical heave is $15.99 \mathrm{~mm}$ for the model without riprap and
$9.99 \mathrm{~mm}$ for the model with riprap by decreasing the ratio by approximately $40 \%$ (Fig. 6A).

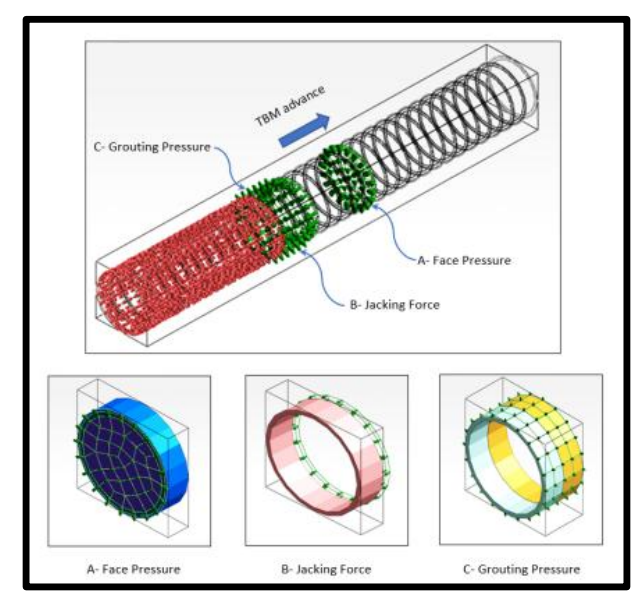

Fig. (3A). Construction loads.

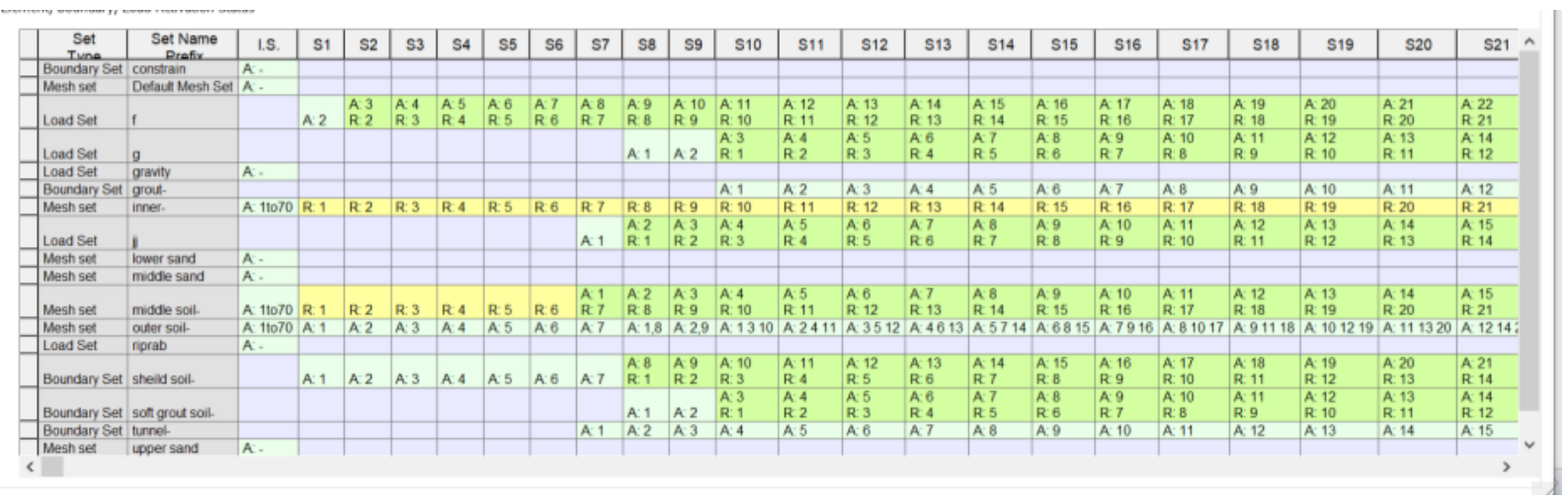

Fig. (4A). Construction stages.

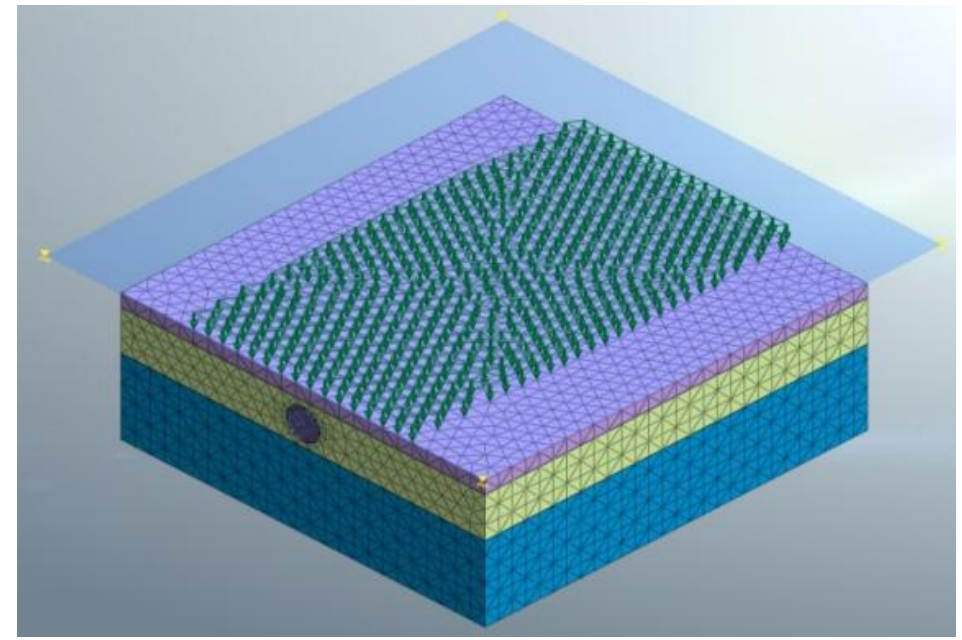

Fig. (5A). Backfilling load. 


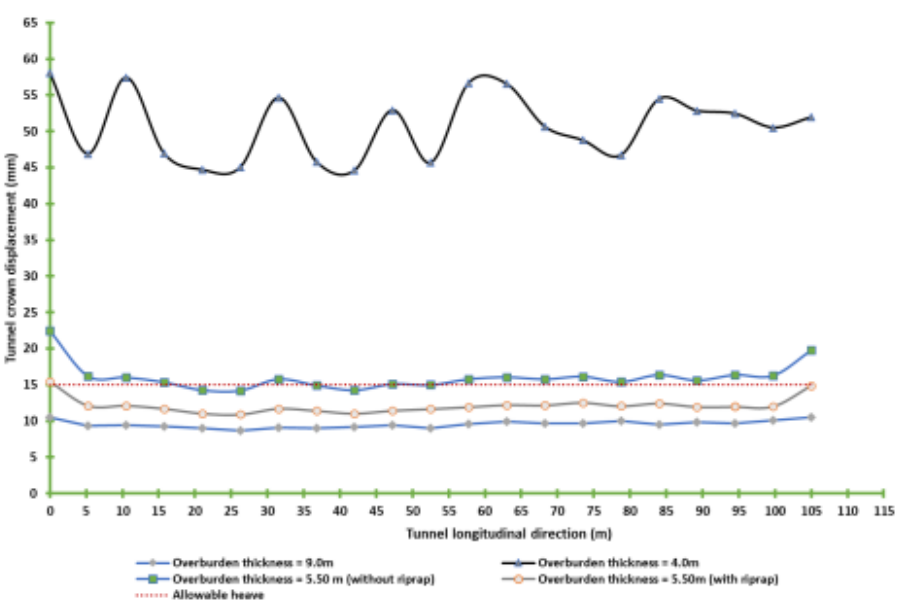

Fig. (6A). Displacement of tunnel crown during construction.

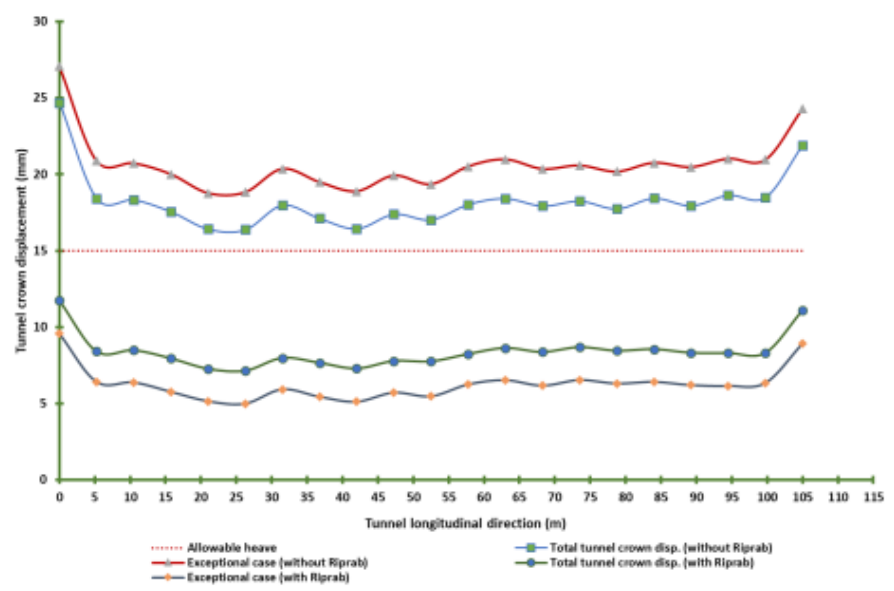

Fig. (7A). Displacement of tunnel crown during service.

For the exceptional case, the total crown vertical heave is $18.26 \mathrm{~mm}$ for the model without riprap and $8.38 \mathrm{~mm}$ for the model with riprap by decreasing the ratio by approximately 54\% (Fig. 7A).

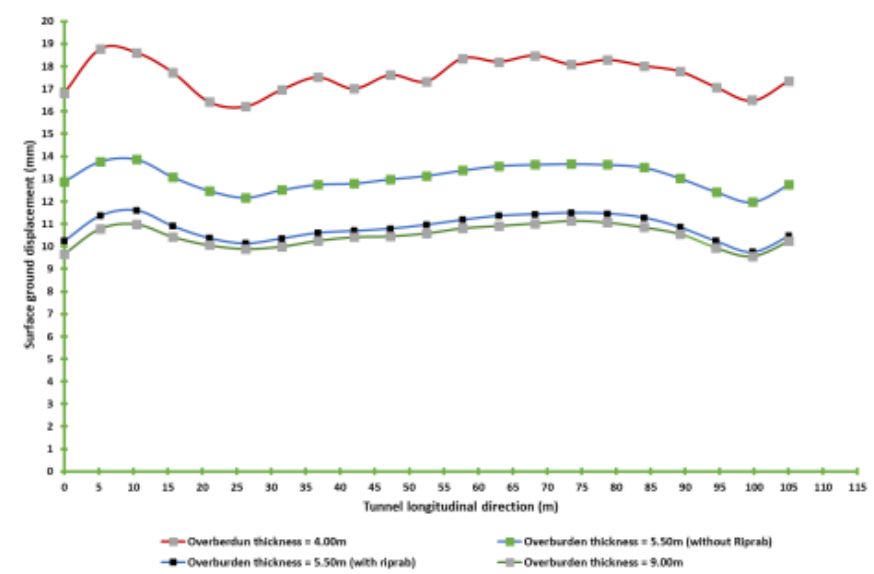

Fig. (8A). Displacement of surface ground during construction. 


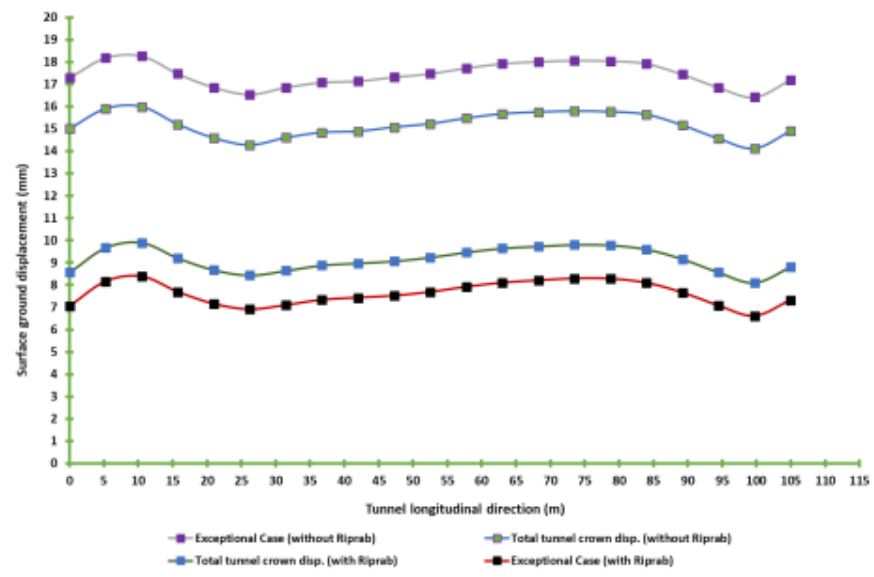

Fig. (9A). Displacement of surface ground during service operation.

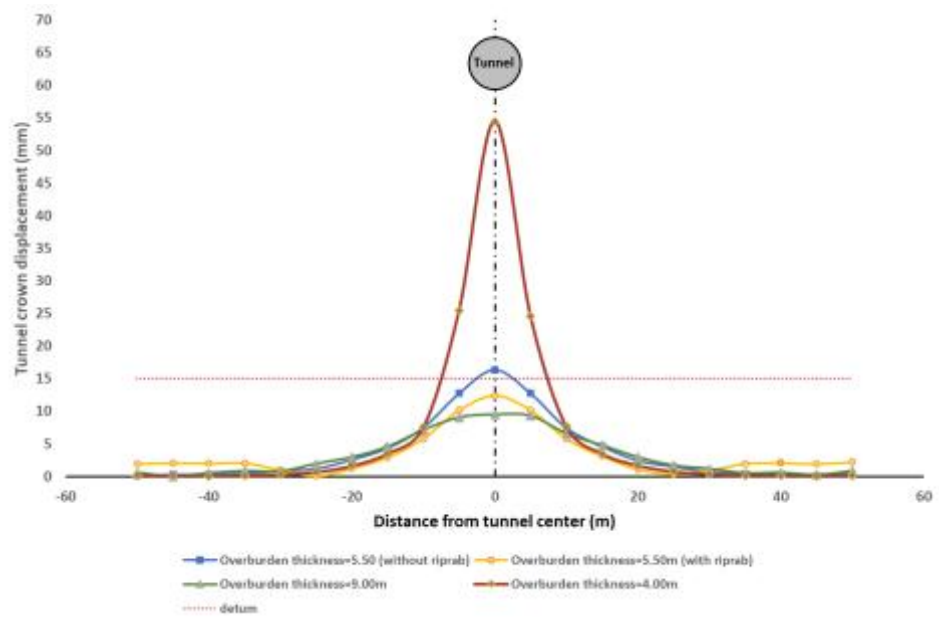

Fig. (10A). Settlement trough during the construction stage.

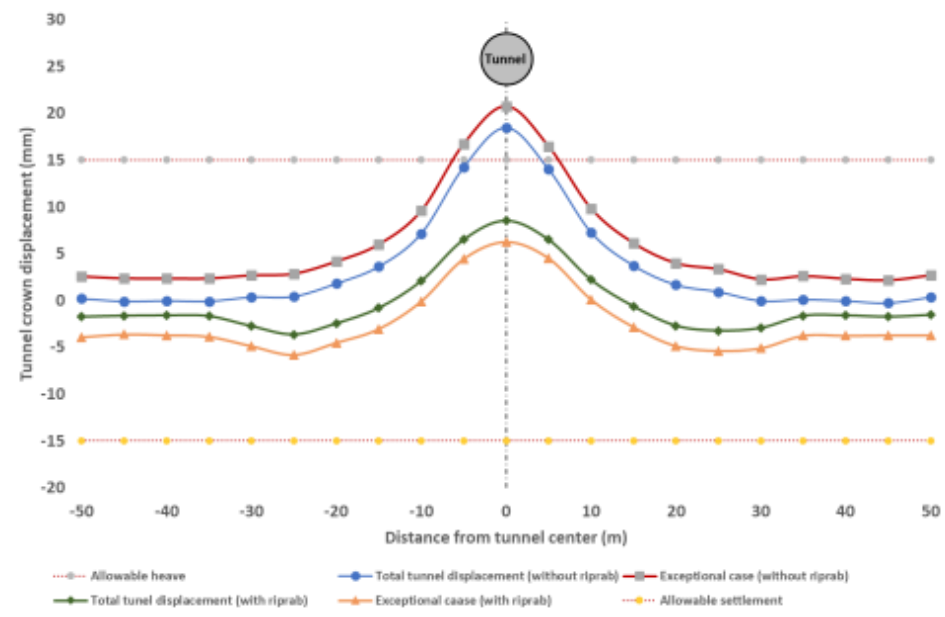

Fig. (11A). Settlement trough during the service stage.

\section{CONCLUSION}

The surface displacement should be less than the design value $( \pm 15 \mathrm{~mm})$. If the cover begins approximately one diameter ahead of the tunnel face, the crown vertical displacement value is about $10.50 \mathrm{~mm}$. 
For model with cover thickness $5.5 \mathrm{~m}$ with/without riprap, the following is noticed:

- The surface heave decreases by $21-31 \%$ during construction, as shown in Figs. (7A and 9A).

- The surface heave decreases by $59-65 \%$ for shortterm and long-term combinations, as shown in Figs. (8A and 11A).

- For the models during the exceptional case, the surface heave decreases by $63-73 \%$, as shown in Figs. (8A and $\mathbf{1 0 A})$.

\section{CONSENT FOR PUBLICATION}

Not applicable.

\section{FUNDING}

None.

\section{CONFLICT OF INTEREST}

The authors declare no conflict of interest, financial or otherwise.

\section{ACKNOWLEDGEMENTS}

Declared none.

\section{REFERENCES}

[1] D.M. Potts, and L. Zdravković, Finite element analysis in geotechnical engineering: Application., Thomas Telford, 2001.

[2] M.S. Keskin, M. Laman, and T. Baran, "Experimental determination and numerical analysis of vertical stresses under square footings resting on sand", Teknik Dergi, vol. 19, no. 4, pp. 4521-4538, 2008.

[3] E. Hoek, and E.T. Brown, "Empirical strength criterion for rock masses", J. Geotech. Geoenviron. Eng., vol. 106, pp. 1013-1035, 1980.

[4] E. Hoek, "Strength of jointed rock masses", Geotechnique, vol. 33, no. 3, pp. 187-223, 1983.

[http://dx.doi.org/10.1680/geot.1983.33.3.187]

[5] E.T. Brown, "Estimating the mechanical properties of rock masses", In: Y Potvin, J Carter, A Dyskin, and R Jeffrey, Eds., Proceedings of 1st Southern Hemisphere International Rock Mechanics Symposium, Australian Centre for Geomechanics: Perth, 2008, pp. 3-22. [http://dx.doi.org/10.36487/ACG_repo/808_16]

[6] J.B. Walsh, and W.F. Brace, "A fracture criterion for brittle anisotropic rock", J. Geophys. Res., vol. 69, no. 16, pp. 3449-3456, 1964. [http://dx.doi.org/10.1029/JZ069i016p03449]

[7] K. Mogi, "Fracture and flow of rocks under high triaxial compression", J. Geophys. Res., vol. 76, no. 5, pp. 1255-1269, 1971.

[http://dx.doi.org/10.1029/JB076i005p01255]

[8] H.S. Yu, and G.T. Houlsby, "A large strain analytical solution for cavity contraction in dilatant soils", Int. J. Numer. Anal. Methods Geomech., vol. 19, no. 11, pp. 793-811, 1995.

[http://dx.doi.org/10.1002/nag.1610191104]

[9] H.S. Yu, "CASM: A unified state parameter model for clay and sand", Int. J. Numer. Anal. Methods Geomech., vol. 22, no. 8, pp. 621-653, 1998.

[http://dx.doi.org/10.1002/(SICI)1096-9853(199808)22:8<621::AID-N AG937>3.0.CO;2-8]

[10] A. Gens, and D.M. Potts, "Critical state models in computational geomechanics", Eng. Comput., vol. 5, no. 3, pp. 178-197, 1988. [http://dx.doi.org/10.1108/eb023736]

[11] J. Jaky, "The coefficient of earth pressure at rest", J Soci Hungarian Arch Eng, vol. 78, pp. 355-388, 1944.

[12] C.P. Wroth, "In-situ measurements on initial stresses and deformations characteristics", Proceedings of In-Situ Measurements of Soil Properties, vol. 2, pp. 181-230, 1975.

[13] A. Elgamal, and N. Elfaris, "Stability of shield-bored tunnel for the challenge of nile crossing", Infrastructures, vol. 6, p. 147, 2021. [http://dx.doi.org/10.3390/infrastructures6100147]

\section{(C) 2021 Ahmed Elgamal}

This is an open access article distributed under the terms of the Creative Commons Attribution 4.0 International Public License (CC-BY 4.0), a copy of which is available at: https://creativecommons.org/licenses/by/4.0/legalcode. This license permits unrestricted use, distribution, and reproduction in any medium, provided the original author and source are credited. 